\title{
Estimation of Chlorpyriphos in its Formulation (Paraban 20\% EC) by Reversed-Phase HPLC
}

\author{
DEEPTI JOSHI* and N.K.SAND ${ }^{\#}$ \\ *Department of Chemistry,M.B.P.G.College, \\ Kumaun University,Haldwani,Uttaranchal, India. \\ \#Department of Chemistry, College of Basic Sciences and Humanities, \\ G.B.Pant University of Agriculture \&Tecnology, Pantnagar, \\ U.S.Nagar, Uttaranchal, India. \\ deeptiajoshi@yahoo.co.in
}

Received 3 January 2008; Accepted 1 March 2008

\begin{abstract}
A method has been developed for estimation of active ingredient in chlorpyriphos formulation (Paraban 20\% EC). The formulation was extracted in chloroform, dried and resuspended in acetonitrile. The cleanup was performed using $\mathrm{C}_{18}$ SPE cartridge. The active ingredient was estimated using $5 \mu \mathrm{m}$ ODS-II column, mobile phase was acetonitrile: water $(75: 25 \mathrm{v} / \mathrm{v})$ and detection at $229 \mathrm{~nm}$. The efficiency of clean up method was found to be $95 \%$ and minimum limit of detection $<2.5 \mathrm{ng}$. The detector response was linear with in concentration range $2.5 \mathrm{ng}-50 \mathrm{ng}$ at RSD $1.42 \%$.
\end{abstract}

Keywords: Emulsified concentrate; Solid phase extraction; Relative standard deviation; Chlorpyriphos formulation.

\section{Introduction}

Chlorpyriphos is an organophosphate non-systemic insecticide with contact, stomach and fumigant action. It is used to control household pests including mites, ants etc. and many types of insect's pests in a wide range of croups and ornamentals. Its commercially available formulations are DP, EC, GR, WP and microcapsules etc.

The successful employment of any pesticide depends upon stabilities of its formulation. Every formulation contains a toxicants mixed with an inert diluents or carrier. The active ingredient in a formulation sometime does not contain the reported concentration In order to check passage of spurious/sub-standard formulation to the consumer, it is necessary to develop a method for estimation of active ingredient in a formulation. 
A few method have been reported for the estimation of chlorpyriphos in its formulation by gas liquid chromatography (GLC) using acetonitrile - water - THF - glacial acetic acid and - monoathanolamine and detection at $230 \mathrm{~nm}$ photodiode array detector using butylated hydroxytoluene as an internal standard ${ }^{1}$; study of persistence of chlorpyriphos on apple by gas chromatography using electron capture detector ${ }^{2}$; gas chromatographic determination of chlorpyriphos residues in milk $^{3}$; study of screening of chlorpyriphos by HPTLC and GC/MS ${ }^{4}$; ultraviolet spectrophotometry for determination of chlorpyriphos ${ }^{5}$; analysis of metabolites of chlorpyriphos formulation in various plants grown in greenhouse by TLC. However, no method for extraction, clean up and estimation of chlorpyriphos in its formulation "Paraban 20\% EC" by reversed - phase HPLC is available.

\section{Experimental}

\section{Chemicals}

The formulation chlorpyriphos "Paraban 20\% EC" was manufactured by M/S Ashok Pesticides, Baroda. The technical sample was recrystallized prior to use. All the solvents used were of analytical grade (AR) or HPLC grade. Triple distilled water was prepared in the laboratory by double distillation of single metal distilled water in all quartz double distillation assembly.

\section{Instruments}

SPE cartridge ENV1 $\left(\mathrm{C}_{18}\right)$ pre-packed with $500 \mathrm{mg}$ packing material, capacity $6 \mathrm{~mL}$ (Supelco, USA), Beckman HPLC with ODS-II column and detection at $229 \mathrm{~nm}$ etc.

\section{Formulation Analysis}

\section{Extraction}

For the estimation of active ingredient in formulation (Paraban 20\% EC); a stock solution of formulation was performed by dissolving $0.5 \mathrm{~g}$ of $20 \% \mathrm{EC}$ in $100 \mathrm{~mL}$ chloroform. From $1000 \mathrm{ppm}$ solution, serial dilution was made to prepare $100 \mathrm{ppm}$ and $50 \mathrm{ppm}$, which were for further clean up. $5 \mathrm{~mL}$ of this solution was pipette out in to graduated test tubes with the help of pi-pump and dried using flash evaporator at about $50^{\circ} \mathrm{C}$. The residue thus obtained was redissolved in $5 \mathrm{~mL}$ acetonitrile.

\section{Clean up}

The clean up of formulation extract was done using C18 SPE cartidge. The column was washed with $5 \mathrm{~mL}$ acetonitrile and $0.5 \mathrm{~mL}$ solution of formulation was eluted with $\mathrm{CH}_{3} \mathrm{CN}: \mathrm{H}_{2} \mathrm{O}(80: 20 \mathrm{v} / \mathrm{v})$ in graduated tube, dried with flash evaporator and resuspended in $5 \mathrm{~mL}$ mobile phase, $\mathrm{CH}_{3} \mathrm{CN}: \mathrm{H}_{2} \mathrm{O}(75: 25 \mathrm{v} / \mathrm{v})$. A $5 \mu \mathrm{L}$ aliquot was injected into HPLC. The active ingredient content in for in formulation was calculated using calibration curve.

\section{HPLC}

After clean up, HPLC for 2.5ng formulation extract was done on ODS guard cartridge $(1 \mathrm{~cm} \times 4.6 \mathrm{~mm}, i . d$. $)$ using mobile phase acetonitrile: water $(75: 25 \mathrm{v} / \mathrm{v})$ at a flow rate of 1.0 $\mathrm{mL} \mathrm{min}^{-1}$, and the UV detection at $229 \mathrm{~nm}$, aufs 0.01 .A $5 \mathrm{~mL}$ volume of sample were injected each time of fixed loop injection and chromatograms were recorded by Kipps and Zonen, BD - 40 recorder. 
Mobile phase and samples were filtered through 0.2 micro filter. A specimen chromatogram of chlorpyriphos formulation after clean up is shown in (Figure 1).

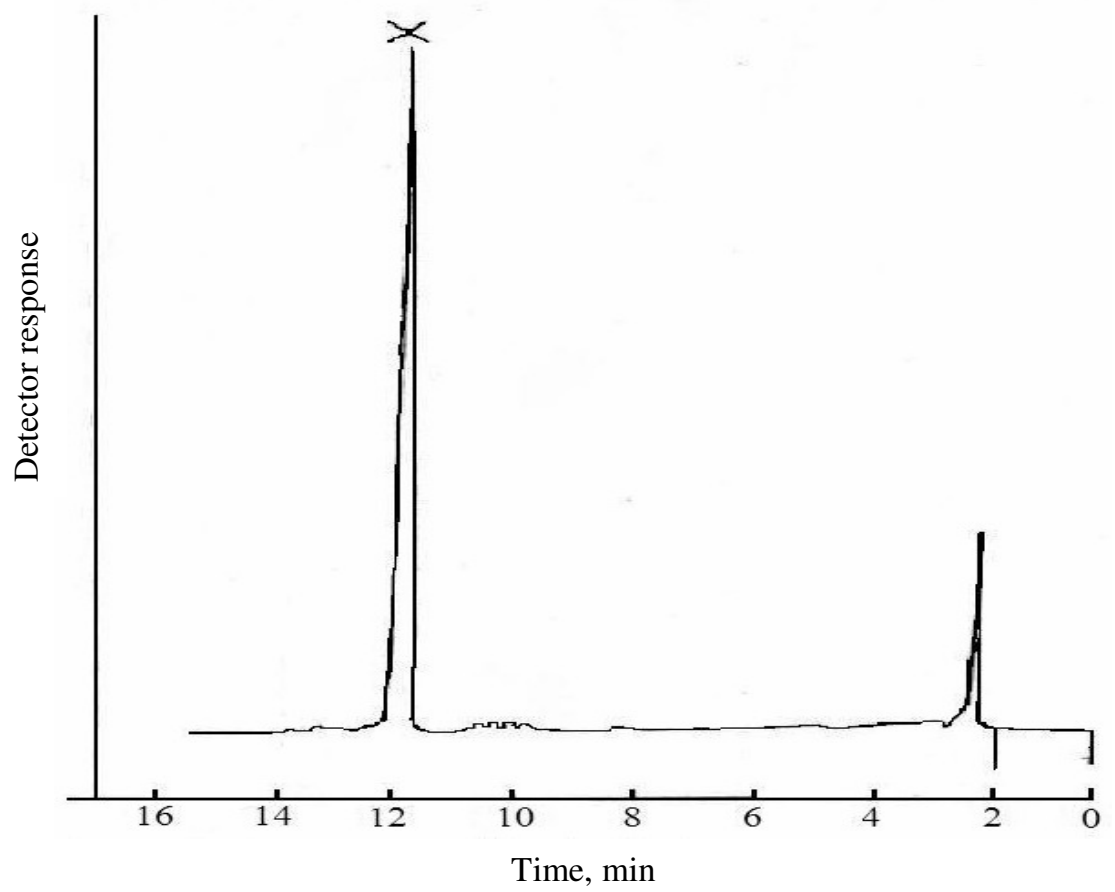

Figure 1. Chromatogram of chlorpyriphos formulation 205 EC after extraction and clean up

\section{Calibration curve}

A stock solution of $100 \mathrm{ppm}$ of recrystallised was made by dissolving $10 \mathrm{mg}$ in $100 \mathrm{~mL}$ mobile phase $\mathrm{CH}_{3} \mathrm{CN}: \mathrm{H}_{2} \mathrm{O}(75: 25 \mathrm{v} / \mathrm{v})$. This stock solution was serially diluted to $10,8.0$, 5.0, 2-0, 1.0 and 0.5 ppm solutions. Five microlitre of each concentration was injected into HPLC in triplet. The average detector response in terms of peak area of each concentration was used for plotting the graph. The calibration curve is shown in (Figure 2).

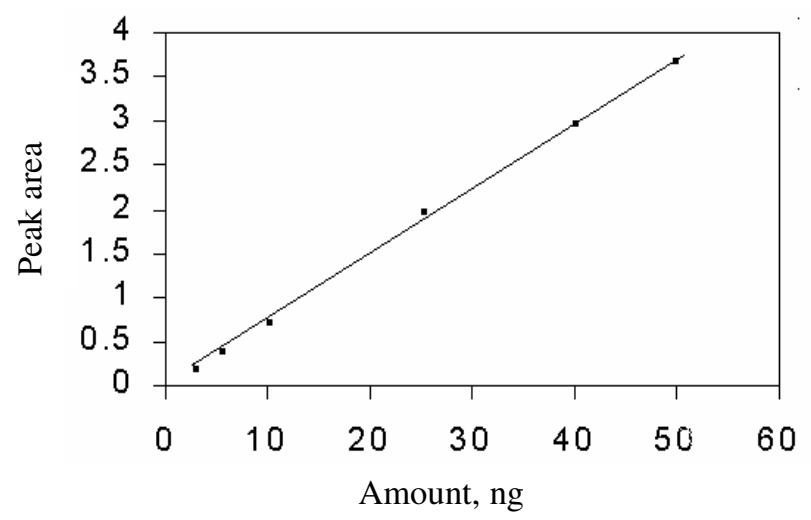

Figure 2. Calibration curve of chlorpyriphos 


\section{Results and Discussion}

UV scan of chlorpyriphos revealed that its absorption maxima $\left(\lambda_{\max }\right)$ was at $229 \mathrm{~nm}$, therefore, the detector was operated at this wavelength.

The chromatograms obtain using mobile phase, acetonitrile: water $(75: 25 \mathrm{v} / \mathrm{v})$ at a flow rate of $1.0 \mathrm{~mL} \mathrm{~min}^{-1}$, showed no interfering peak at the retention time of the chlorpyriphos i.e. 11.2 minute (Figure 1).

The detector response was linear (Figure 1) with in concentration range 2.5 - $50 \mathrm{ng}$ at RSD $1.42 \%$. The clean up by C18 columns gave recovery of $95.25 \%$. The active ingredient in the formulation was found to be $18.36 \%$. The standard deviation (S) for the data was 0.1344 , where as coefficient of variance $(\mathrm{Cv})$ was $0.732 \%$ (Table 1$)$. The lower amount of active ingredient in the formulation may be due to dissipation of active ingredient during storage.

Table 1. Active ingredient of formulation "Paraban 20\% EC" and statistical analysis

\begin{tabular}{cccc}
\hline $\begin{array}{c}\text { Active Ingredient, } \\
\%\end{array}$ & $\mathrm{M}($ mean $), \%$ & $\pm \mathrm{M}_{\mathrm{n}}-\mathrm{m}$ & $\sum \mathrm{M}_{\mathrm{n}}-\mathrm{m}$ \\
\hline 18.31 & \multirow{2}{*}{18.36} & 0.05 & \\
18.31 & & 0.05 & 0.19 \\
18.31 & & 0.05 & \\
\hline
\end{tabular}

\section{Conclusion}

The method developed in this study may be used for determination of active ingredient in the formulation of chlorpyriphos "Parabon $20 \%$ EC".

\section{References}

1. Bushway R J, Perkins L B and King J M, Journal of the Association of Official Analytical Chemists, 1988, 71(2), 321-322.

2. $\quad$ Nath A, Patyal S K and Sharma I D, J Pesticide Research, 1997.9 (1), 92-96.

3. Lubs M, Hamann J and Heeschen W, Milchwissens, 1983, 38 (10).

4. Park S W, Jang S G, Park O S, Lee J H, Lee S K, You J H, Kim D H, Jin K H, Kim K W, Kim Y N and Cho, Anal Sci Technol., 2000, 13(1), 108 - 120.

5. Ali S S, Haq R U, khalid M and Shakoori A R, Punjab Univ J Zool., 1997, 12, 31 - 34.

6. Smith G N, Watson B S and Fischer F S, J Agric Food Chem., 1967, 15, 127 - 131. 


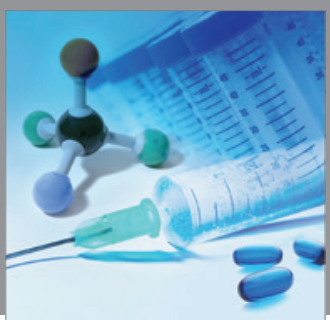

International Journal of

Medicinal Chemistry

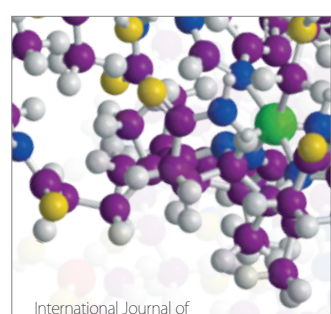

Carbohydrate Chemistry

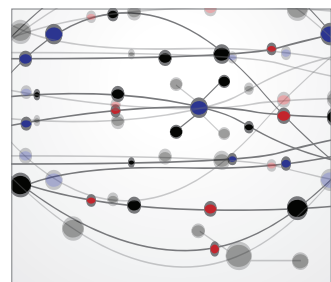

The Scientific World Journal
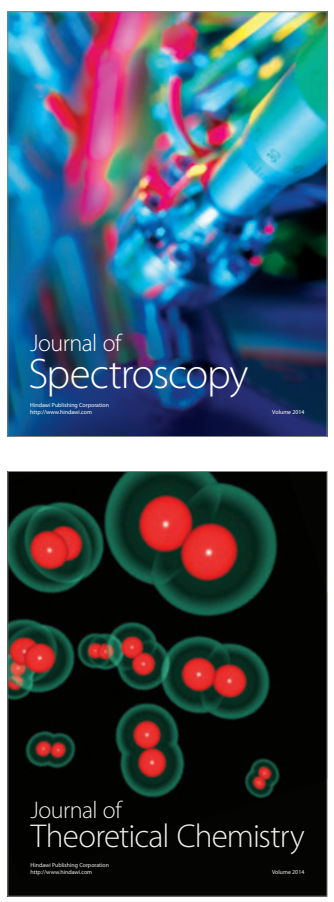
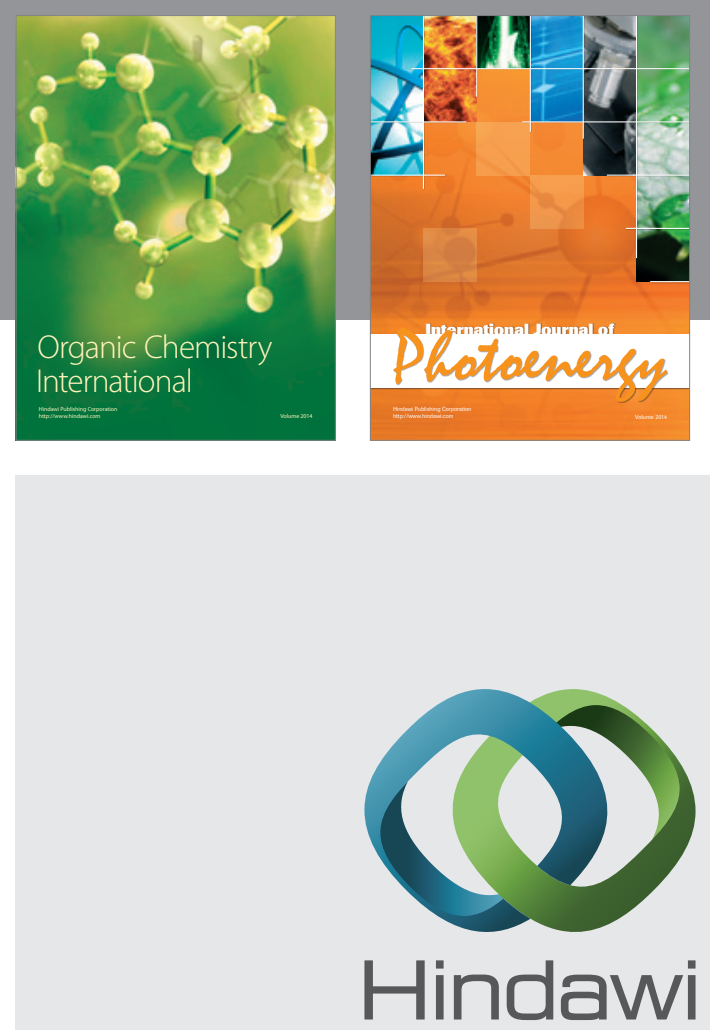

Submit your manuscripts at

http://www.hindawi.com
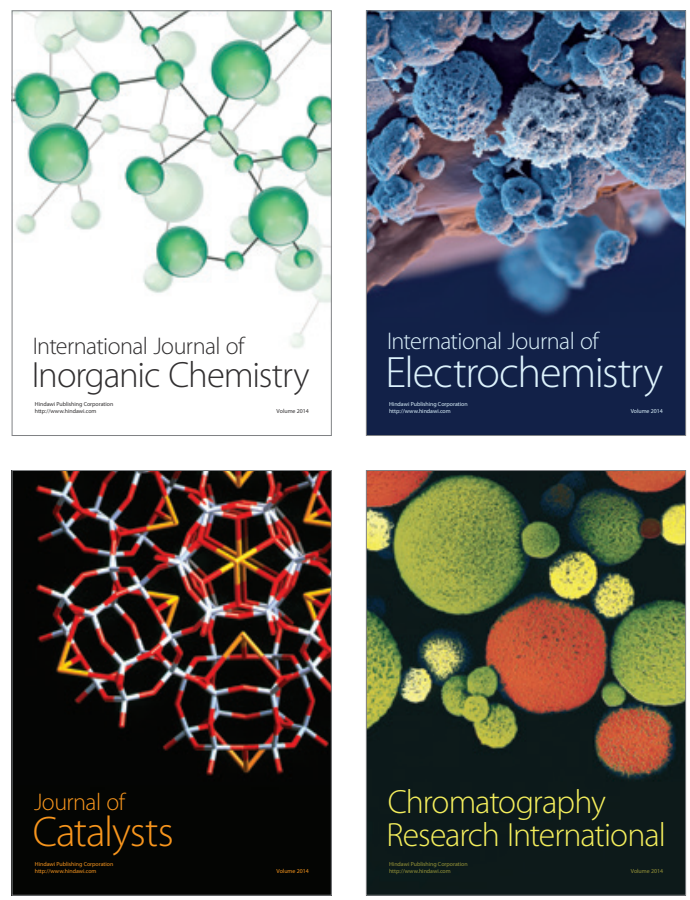
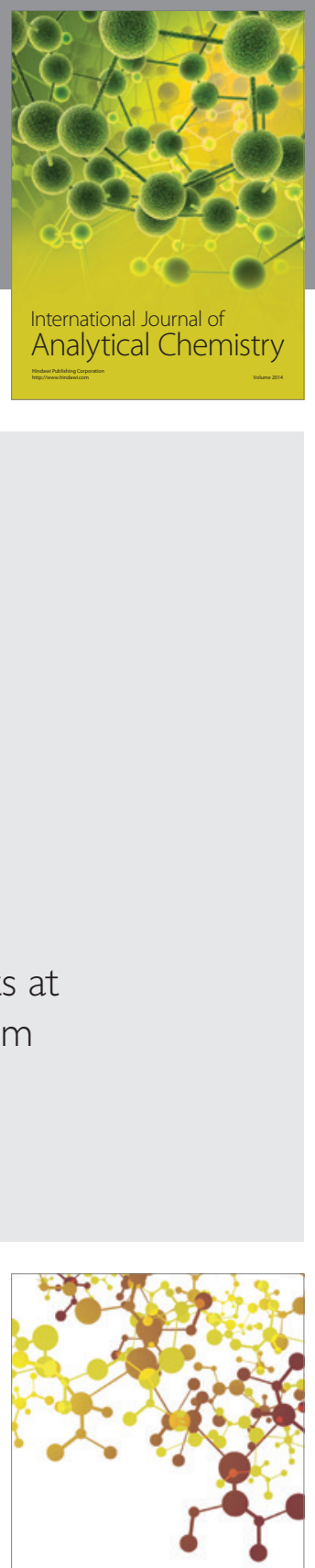

Journal of

Applied Chemistry
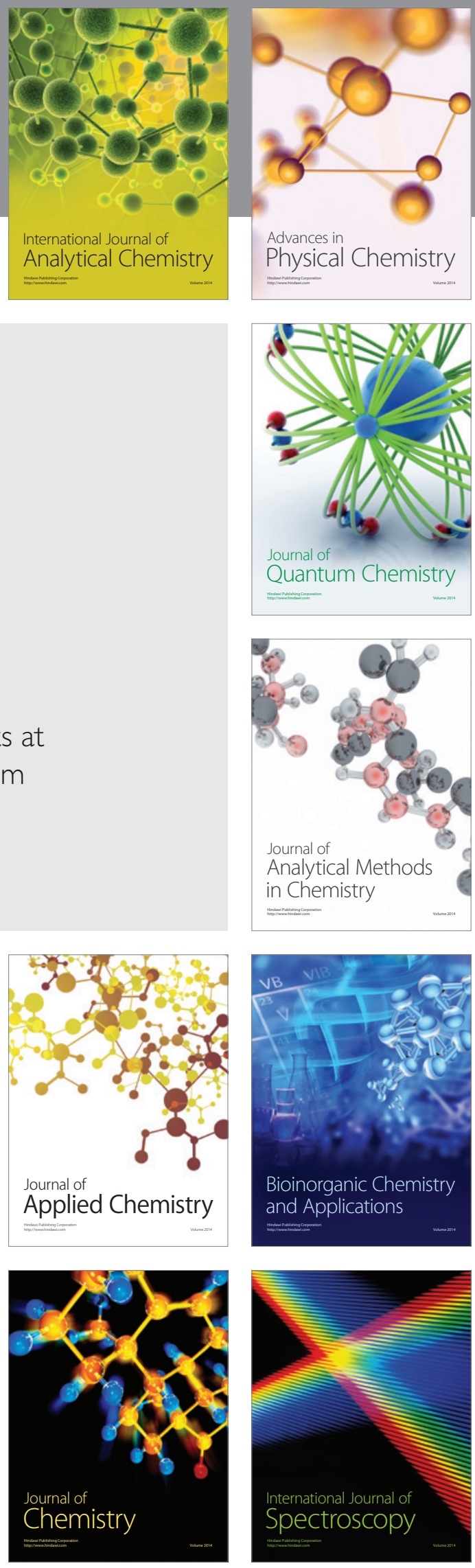